\title{
Two Different Causes of Paediatric Hypercalcaemia
}

"Stepan Kutilek, ${ }^{1}$ Ivana Plasilova, ${ }^{2}$ Viktor Chrobok ${ }^{3}$

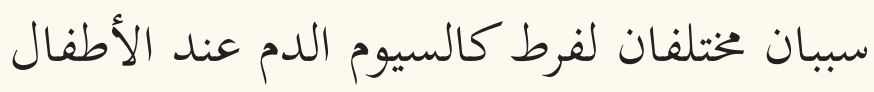

ستيفان كوتليك، إيفانا فالسيلوفا، فيكتور شروبوك

ABSTRACT: Paediatric hypercalcaemia is a rare condition which can be easily overlooked or misdiagnosed. We report two paediatric patients who presented to the Department of Paediatrics, Pardubice Hospital, Pardubice, Czech Republic, in 2009 and 2010, respectively. Each patient was diagnosed with hypercalcaemia due to a different cause. The first case involved a seven-month-old infant who presented with failure to thrive, vomiting and psychomotor retardation. Fluorescent in situ hybridisation revealed Williams-Beuren syndrome. The second patient was a 16-year-old girl with abdominal pain and renal colic due to hypercalcaemia-induced urolithiasis. High parathyroid hormone serum levels suggested primary hyperparathyroidism. An adenoma of the left upper parathyroid gland was diagnosed via technetium-99m-labelled methoxyisobutyl isonitrile single photon emission computed tomography and removed surgically. Hypercalcaemia should be considered in the differential diagnosis of various disease states, particularly among infants who fail to thrive or children with abdominal pain.

Keywords: Hypercalcemia; Williams-Beuren Syndrome; Hyperparathyroidism; Parathyroid Adenoma; Case Report; Czech Republic.

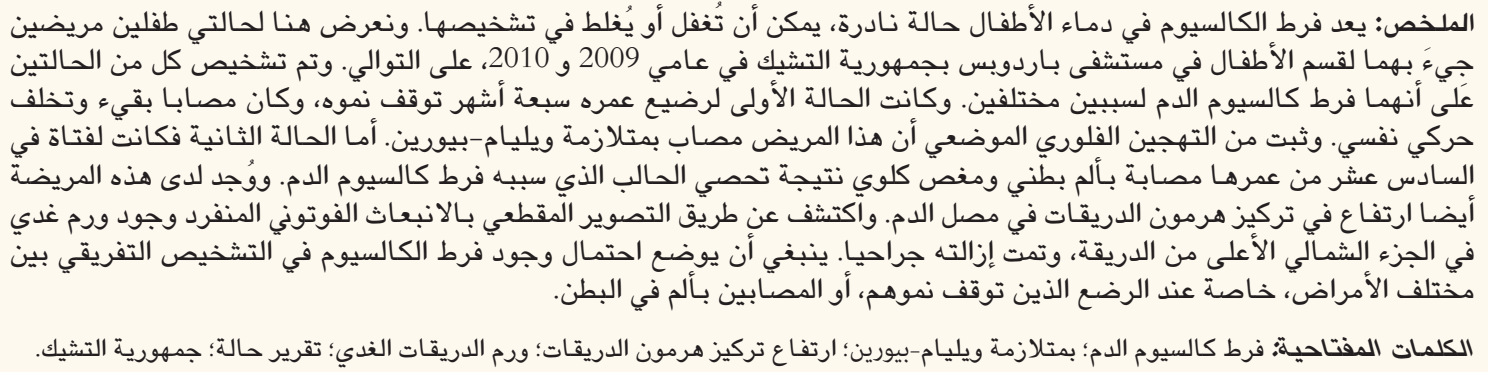

$\mathrm{H}$ ypercalcaemia is defined as Serum calcium (S-Ca) levels of $>2.7 \mathrm{mmol} / \mathrm{L}$, with $\mathrm{S}-\mathrm{Ca}$ levels of $>3.0 \mathrm{mmol} / \mathrm{L}$ requiring therapeutic intervention and those of $>3.5 \mathrm{mmol} / \mathrm{L}$ considered life-threatening and requiring immediate action. ${ }^{1-4}$ Treatment consists of ensuring adequate hydration and administering glucocorticoids, diuretics (i.e. furosemide) and bisphosphonates (e.g. pamidronate or zoledronate). Vitamin D and calcium supplementation should be avoided, as well as exposure to sunshine. ${ }^{1-3}$

Hypercalcaemia in childhood is rare and may have different origins, including vitamin D intoxication, hyperparathyroidism, hyperthyroidism, granulomatous disease, Williams-Beuren syndrome, calcium-sensing receptor mutations, Jansen's metaphyseal chondrodysplasia, hypophosphatasia, subcutaneous fat necrosis and humoral or osteolytic malignancy. ${ }^{1-3}$ A complete evaluation of blood minerals together with assessments of serum alkaline phosphatase (S-ALP) activity and parathyroid hormone
(S-PTH) levels usually helps to ensure the correct diagnosis. This case report describes two cases of paediatric hypercalcaemia arising from different causes, one case in an infant and the other in an adolescent girl.

\section{Case One}

A seven-month-old girl was referred to the Department of Paediatrics, Pardubice Hospital, Pardubice, Czech Republic, in 2009 due to lethargy, psychomotor retardation, muscle hypotonia, anorexia, vomiting, constipation and failure to thrive. Her family and perinatal history was normal, with a 41-week gestational period, birthweight of 3,670 g, birth length of $50 \mathrm{~cm}$ and Apgar scores of 6-9. Up until the age of five months, her rate of weekly weight gain had been normal at 150-200 g; however, between months five and six, she gained only $100 \mathrm{~g}$ (from $7,200 \mathrm{~g}$ to 7,300 g) and between months six and seven, she lost $460 \mathrm{~g}$ (from 7,300 g to 6,840 g). She was being 
Table 1: Blood biochemistry results of case one

$\begin{array}{lcc}\text { Serum levels } & \text { Result } & \text { Normal range* } \\ \text { Calcium in mmol/L } & 3.8 & 2.2-2.6 \\ \text { Sodium in mmol/L } & 134 & 135-145 \\ \text { Potassium in } \mathrm{mmol} / \mathrm{L} & 3.7 & 3.5-5.0 \\ \text { Phosphorus in mmol/L } & 1.13 & 1.1-2.2 \\ \text { Magnesium in mmol/L } & 0.7 & 0.6-1.1 \\ \text { ALP in } \mu \mathrm{kat} / \mathrm{L} & 1.5 & 2.2-9.3 \\ \text { Creatinine in } \mu \mathrm{mol} / \mathrm{L} & 52 & 20-40 \\ \text { PTH in ng/L } & 4.8 & 15-65 \\ \text { 25-OH vitamin } \mathrm{D} \text { in } \mathrm{nmol} / \mathrm{L} & 72 & 75-125\end{array}$

$A L P=$ alkaline phosphatase; $P T H=$ parathyroid hormone; $\mathrm{OH}=$ hydroxy. *Age-specific reference range.

breastfed, administered infant formula and vegetable soup and was receiving regular antirachitic prophylaxis (oral cholecalciferol at $500 \mathrm{IU} /$ day). Upon admission, blood biochemistry tests revealed high levels of S-Ca (3.8 $\mathrm{mmol} / \mathrm{L})$, low levels of S-ALP $(1.5 \mu \mathrm{kat} / \mathrm{L})$, mildly elevated serum creatinine levels $(52 \mu \mathrm{mol} / \mathrm{L})$ and low S-PTH levels (4.8 ng/L). Other biochemistry results were normal [Table 1].

Echocardiography revealed very mild pulmonary artery stenosis (gradient of $10-15 \mathrm{mmHg}$ ) and nephrocalcinosis was apparent on a renal ultrasound. However, a wrist X-ray was normal, without any osteolytic signs. The combination of hypercalcaemia, normophosphataemia and low S-PTH and S-ALP levels ruled out primary hyperparathyroidism (HPT); additionally, vitamin D intoxication was excluded by the low-to-normal 25-hydroxyvitamin D levels. Accordingly, idiopathic infantile hypercalcaemia was suspected and, on the second day of admission, the patient received an intravenous infusion of $0.9 \%$ sodium chloride with $5 \%$ dextrose together with methylprednisolone and furosemide $(2 \mathrm{mg} / \mathrm{kg} /$ day each). This resulted in a gradual decrease in
S-Ca levels (from 3.54 to $3.02 \mathrm{mmol} / \mathrm{L}$ and $2.4 \mathrm{mmol} / \mathrm{L}$, respectively) within 48 hours. One week after admission, the patient was discharged with a bodyweight of 7,300 g. She continued receiving a low-calcium milk-free diet ( $\leq 200 \mathrm{mg}$ of calcium/day), primarily consisting of vegetable soup, poultry, mixed fruit and pastries, with no vitamin D supplementation. Her S-Ca levels remained between $2.25-2.6 \mathrm{mmol} / \mathrm{L}$; however, after an isolated attempt to reintroduce milk at the age of eight months, her S-Ca levels increased transiently to $3.5 \mathrm{mmol} / \mathrm{L}$ [Figure 1A].

Despite the normalisation in her S-Ca levels, the patient's psychomotor development remained slow and the muscle hypotonia persisted. Furthermore, her weight gain rate remained inappropriately low. She had no apparent dysmorphic facial features. Accordingly, at the age of 11 months, the patient underwent fluorescent in situ hybridisation (FISH) which revealed a chromosome 7q11.23 deletion indicative of WilliamsBeuren syndrome. This was confirmed when 'elfin' facial features became apparent at the age of one year (i.e. a broad forehead, stellate iris pattern, flat nasal bridge, full cheeks and lips, long smooth philtrum and wide mouth). In the following years, she displayed behaviour characteristic of Williams-Beuren syndrome (i.e. over friendliness, empathy, generalised anxiety, specific phobias and attention deficit disorder). ${ }^{5-8}$ From the age of 10 months, her blood S-Ca levels rem-ained normal. At the time of writing, the patient was nine years old and under close surveillance. Although mildly to moderately developmentally delayed, her anthropometric data were within normal reference ranges for the syndrome. ${ }^{8}$

\section{Case Two}

A 16-year old girl was admitted to the Department of Paediatrics, Pardubice Hospital, in 2010 with complaints of recurrent abdominal pain. Her family and personal
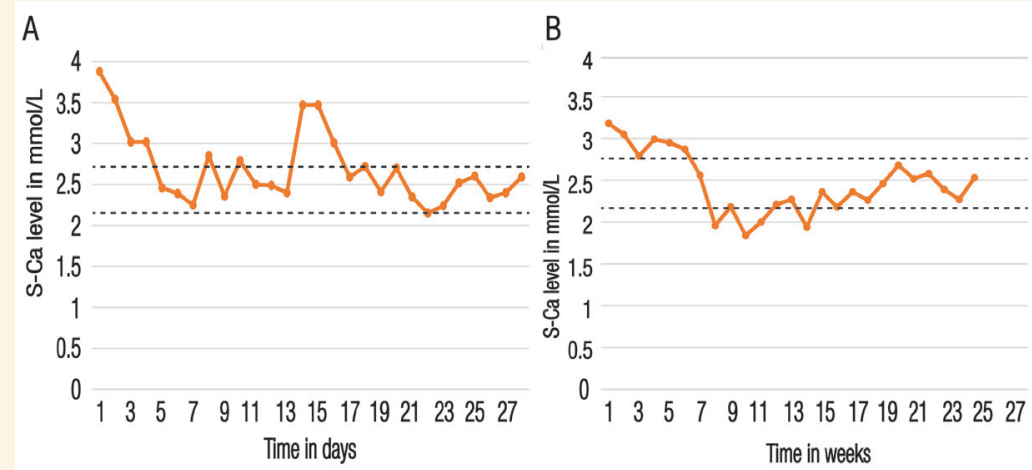

Figure 1: Serum calcium changes over time for (A) case one and (B) case two. The dotted lines represent the upper and lower reference values.

S-Ca = serum calcium. 
history was normal. One week prior, a urinalysis had revealed proteinuria and microscopic haematuria and she had been provisionally diagnosed with a urinary tract infection and prescribed painkillers and amoxicillin/clavulanate by a general practitioner. This resulted in temporary cessation of the pain. However, the abdominal pain and microscopic haematuria recurred and she was admitted to hospital. Upon admission, her blood pressure was normal (120/80 $\mathrm{mmHg}$ ) and an abdominal X-ray and ultrasound examination failed to show any concrements, although dilation of the left renal pelvis and ureter was apparent. Laboratory results revealed high S-Ca levels of $3.2 \mathrm{mmol} / \mathrm{L}$, normal phosphorus levels of $0.9 \mathrm{mmol} / \mathrm{L}$ (normal age-specific range: $0.7-1.5 \mathrm{mmol} / \mathrm{L}$ ), normal SALP levels of $1.5 \mu \mathrm{kat} / \mathrm{L}$ (normal age-specific range: $0.7-2.5 \mu \mathrm{kat} / \mathrm{L}$ ) and high S-PTH levels of $126.0 \mathrm{ng} / \mathrm{L}$ (normal age-specific range: 15.0-65.0 ng/L). A helical computed tomography (CT) scan revealed a $3-\mathrm{mm}$ urolithiasis which was voided spontaneously.

Multiple endocrine neoplasia (MEN) types I and II and a jaw tumour were ruled out as the patient's thyrotropin and free thyroxin levels were normal, along with magnetic resonance imaging (MRI) of the brain, skull and abdomen. A diagnosis of primary HPT was established. As a technetium-99m ( $\left.{ }^{99} \mathrm{Tc}\right)$-labelled methoxyisobutyl isonitrile (MIBI) scan showed only mild accumulation at the upper left parathyroid gland, ${ }^{99} \mathrm{Tc}-\mathrm{MIBI}$ single photon emission CT (SPECT) was performed; this confirmed left upper parathyroid enlargement, most probably due to an adenoma. This was also corroborated by MRI and a neck ultrasound. As measured by dual X-ray absorptiometry, her bone mineral density was within normal limits for her age. She was prescribed $20 \mathrm{mg} /$ day of furosemide and her S-Ca levels dropped below $3 \mathrm{mmol} / \mathrm{L}$ within one week.

Two months later, the patient underwent a parathyroidectomy of the left upper parathyroid gland [Figure 2].

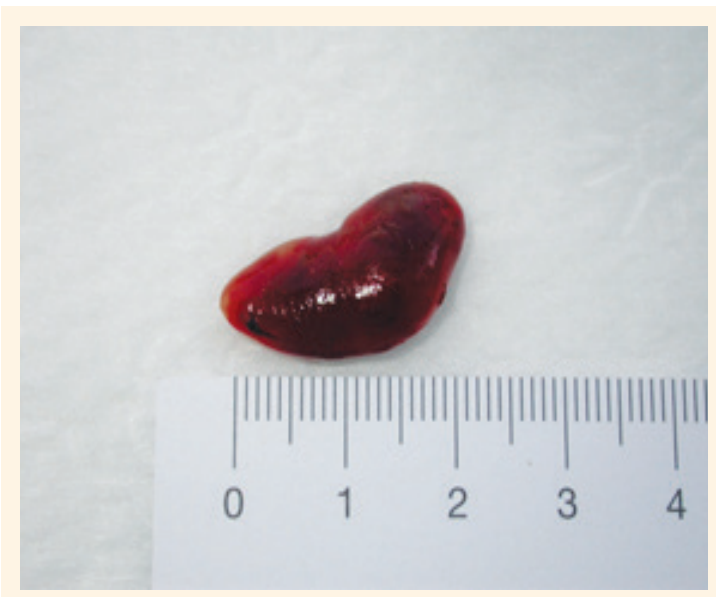

Figure 2: Gross photograph of a parathyroid adenoma excised from a 16-year-old girl with recurrent abdominal pain and hypercalcaemia.
Histological evaluation confirmed the diagnosis of an adenoma. Subsequently, her S-PTH levels dropped to $15 \mathrm{ng} / \mathrm{L}$ and thereafter remained between 10-20 ng/L. The postoperative course was uneventful over the next three days; however, on the fourth day, the patient developed hungry bone syndrome with a drop in S-Ca levels (1.9 mmol/L) [Figure 1B]. Accordingly, she received calcium $(3,000 \mathrm{mg} /$ day $)$ and cholecalciferol (5,000-7,500 IU/day) supplementation for four months. At the time of writing, the patient was 24 years old, in a good state of health with normal S-Ca levels and was being monitored by an endocrinologist.

\section{Discussion}

Hypercalcaemia should be considered in infants and children with failure to thrive, constipation, hypotonia and psychomotor retardation. In the current case report, the two presented cases of paediatric hypercalcaemia serve as an important clinical reminder of the complex differential diagnosis of mineral metabolism disorders. In the first patient, the underlying cause of hypercalcaemia was Williams-Beuren syndrome, while the second was caused by primary HPT due to an adenoma of the parathyroid gland.

Williams-Beuren syndrome is caused by a 7q11.23 contiguous gene deletion of the Williams-Beuren syndrome critical region that encompasses the elastin gene. ${ }^{5}$ It is transmitted in an autosomal dominant manner and occurs in one in 10,000 live births, of which most cases are de novo. Hypercalcaemia occurs in 15-50\% of affected children, although the specific causative mechanism by which this occurs is currently unknown. ${ }^{5}$ Apart from hypercalcaemia, typical manifestations include congenital heart defects (especially supravalvular aortic and peripheral pulmonary artery stenosis), hypercalciuria with nephrocalcinosis/urolithiasis, endocrine abnormalities (i.e. thyroid hypoplasia, impaired glucose tolerance and growth hormone deficiency), feeding problems, failure to thrive, hypertension, dental anomalies and distinctive facial features and behavioural characteristics, such as irritability, anxiety, overfriendliness and hypersensitivity to noise. ${ }^{6-8}$ However, not all of these are present among affected infants, with certain manifestations only becoming apparent later, usually in early childhood. ${ }^{6}$ While the prognosis is generally good, there is an increased risk of cardiovascular morbidities and patients require periodic monitoring by specialists (i.e. an endocrinologist, cardiologist, neurologist, psychologist, psychiatrist, stomatologist and orthopaedic surgeon). ${ }^{5,8}$

Generally, primary HPT is rare in children and adolescents, constituting less than $5 \%$ of all cases. ${ }^{9-12}$ At the Johns Hopkins Children's Center in Baltimore, Maryland, USA, only 16 paediatric and adolescent patients 
with primary HPT (mean age: $16.3 \pm 2.9$ years) were reported between 1984 and $2001 .^{9}$ In another study from Belgrade, Serbia, there were seven paediatric cases (mean age: 15.7 years) out of 522 patients with primary HPT seen between 2004 and 2010.10 Libánský et al. analysed 10 primary HPT patients between $10-17$ years old between 1996 and 2007.11 Currently, the diagnosis of primary HPT in children and adolescents is mostly incidental. ${ }^{11,12}$ The most frequent manifestation of paediatric primary HPT is urolithiasis in 64\% of cases, with other symptoms including limb pain, fractures, hypertension, fatigue and constipation. ${ }^{1,9-12}$

In the current case report, the second patient presented with renal colic and hypercalcaemia due to a single parathyroid adenoma. Among children, primary HPT is mostly due to a parathyroid adenoma; however, it can also occur within the context of other syndromes, such as parathyroid hyperplasia in MEN types I and II and HPT with jaw tumours. ${ }^{9-12}$ While a ${ }^{99} \mathrm{Tc}-\mathrm{MIBI}$ scan, neck ultrasound and MRI scan can help to localise a parathyroid adenoma, ${ }^{99} \mathrm{Tc}-\mathrm{MIBI}$ SPECT is the most reliable method in this regard. ${ }^{13,14}$ In cases of paediatric parathyroid adenomas, surgical removal is the only effective treatment for primary HPT. ${ }^{11,15}$ However, hungry bone syndrome is a frequent postoperative complication and usually lasts for 3-4 months, with the duration reflecting the time span of bone remodelling. ${ }^{16,17}$

\section{Conclusion}

Hypercalcaemia should be considered in the differential diagnosis for various disease states, especially among infants with psychomotor retardation and failure to thrive and children with abdominal pain, renal colic and urolithiasis.

\section{ACKNOWLEDGEMENTS}

The authors wish to thank Dr Vladimir Nemec, Dr Hana Teterova-Cerna, Dr Olga Machacova, Dr Kristyna Machata-Hanulikova, Dr Katerina Sachova, Dr Iva Lebedova and Dr Petr Munzar who took care of the patients during their stay in hospital as well as Dr Vera Jüttnerova and Dr Jozef Kubinyi who performed the FISH procedure and ${ }^{99} \mathrm{Tc}-\mathrm{MIBI}$ SPECT scan, respectively, in the second case. A poster of the preliminary version of the first case in this case report was presented at the $7^{\text {th }}$ International Conference on Children's Bone Health from 27-30 June 2015 in Salzburg, Austria. An abstract of this poster presentation was subsequently published in Bone Abstracts in 2015 (Volume 4, Issue S3, P. 84).

\section{References}

1. Lietman SA, Germain-Lee EL, Levine MA. Hypercalcemia in children and adolescents. Curr Opin Pediatr 2010; 22:508-15. doi: 10.1097/MOP.0b013e32833b7c23.

2. Davies JH. Approach to the child with hypercalcaemia. Endocr Dev 2015; 28:101-18. doi: 10.1159/000380998.

3. McNeilly JD, Boal R, Shaikh MG, Ahmed SF. Frequency and aetiology of hypercalcaemia. Arch Dis Child 2016;101:344-7. doi: 10.1136/archdischild-2015-309029.

4. Elshafie OT, Woodhouse NJ. The diagnosis and management of severe hypercalcaemia: A simplified approach - Report of five cases. Sultan Qaboos Univ Med J 2010; 10:388-95.

5. Morris CA. Williams syndrome. In: Adam MP, Ardinger HH, Pagon RA, Eds. GeneReviews ${ }^{\circledR}$. From: www.ncbi.nlm.nih.gov/ books/NBK1249/ Accessed: Feb 2018.

6. Sindhar S, Lugo M, Levin MD, Danback JR, Brink BD, Yu E, et al. Hypercalcemia in patients with Williams-Beuren syndrome. J Pediatr 2016; 178:254-60.e4. doi: 10.1016/j.jpeds.2016. 08.027 .

7. Güven A. Seven cases with Williams-Beuren syndrome: Endocrine evaluation and long-term follow-up. J Pediatr Endocrinol Metab 2017; 30:159-65. doi: 10.1515/jpem-2016-0039.

8. Committee on Genetics. American Academy of Pediatrics: Healthcare supervision for children with Williams syndrome. Pediatrics 2001; 107:1192-204.

9. Hsu SC, Levine MA. Primary hyperparathyroidism in children and adolescents: The Johns Hopkins Children's Center experience 1984-2001. J Bone Miner Res 2002; 17:N44-50.

10. Paunovic I, Zivaljevic V, Stojanic R, Kalezic N, Kazic M, Diklic A. Primary hyperparathyroidism in children and young adults: A single institution experience. Acta Chir Belg 2013; 113:35-9. doi: 10.1080/00015458.2013.11680882.

11. Libánský P, Astl J, Adámek S, Nanka O, Pafko P, Spacková J, et al. Surgical treatment of primary hyperparathyroidism in children: Report of 10 cases. Int J Pediatr Otorhinolaryngol 2008; 72:1177-82. doi: 10.1016/j.ijporl.2008.04.005.

12. Lou I, Schneider DF, Sippel RS, Chen H, Elfenbein DM. The changing pattern of diagnosing primary hyperparathyroidism in young patients. Am J Surg 2017; 213:146-50. doi: 10.1016/j.amj surg.2016.03.019.

13. Wei WJ, Shen CT, Song HJ, Qiu ZL, Luo QY. Comparison of SPET/CT, SPET and planar imaging using 99mTc-MIBI as independent techniques to support minimally invasive parathyroidectomy in primary hyperparathyroidism: A meta-analysis. Hell J Nucl Med 2015; 18:127-35. doi: 10.1967/s002449910207.

14. Ozkan ZG, Unal SN, Kuyumcu S, Sanli Y, Gecer MF, Ozcinar B, et al. Clinical utility of Tc-99m MIBI SPECT/CT for preoperative localization of parathyroid lesions. Indian J Surg 2017; 79:312-18. doi: 10.1007/s12262-016-1489-7.

15. Kundel A, Thompson GB, Richards ML, Qiu LX, Cai Y, Schwenk FW, et al. Pediatric endocrine surgery: A 20-year experience at the Mayo Clinic. J Clin Endocrinol Metab 2014; 99:399-406. doi: 10.1210/jc.2013-2617.

16. Ajmi S, Sfar R, Trimeche S, Ben Ali K, Nouira M. Scintigraphic findings in hungry bone syndrome following parathyroidectomy. Rev Esp Med Nucl 2010; 29:81-3. doi: 10.1016/j.re mn.2009.10.003.

17. Witteveen JE, van Thiel S, Romijn JA, Hamdy NA. Hungry bone syndrome: Still a challenge in the post-operative management of primary hyperparathyroidism - A systematic review of the literature. Eur J Endocrinol 2013; 168:R45-53. doi: 10.1530/EJE-12-0528. 